
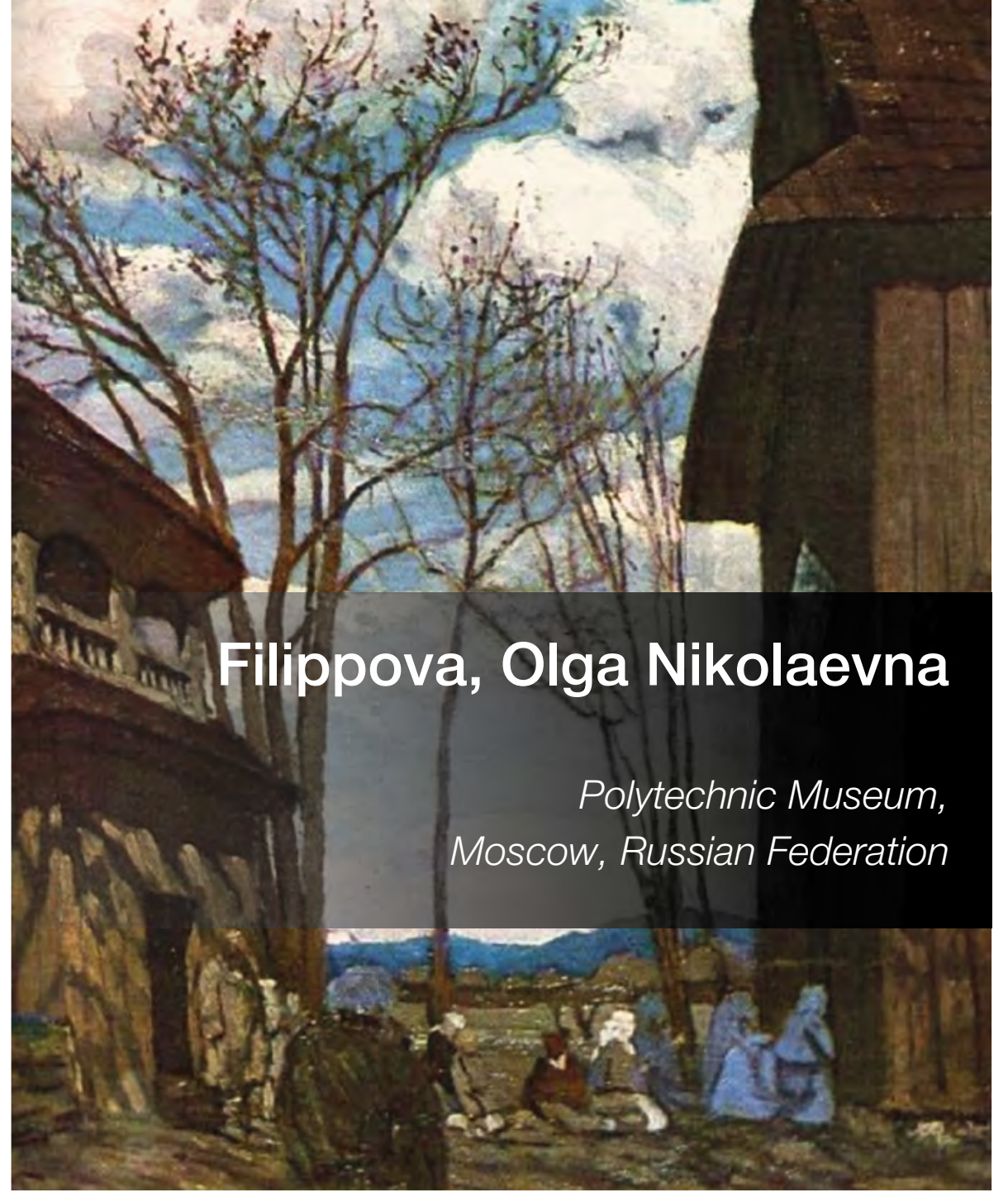

Филиппова Ольга Николаевна

Политехнический музей,

г. Москва, Российская Федерация

\title{
ПЕЙЗАЖ В ТВОРЧЕСТВЕ \\ ФЕРДИНАНДА РУЩИЦА
}

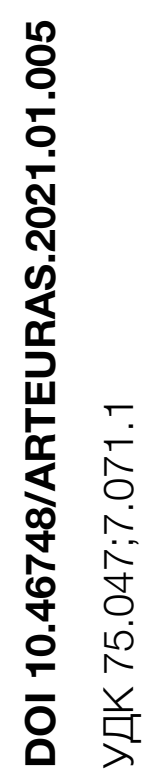




\section{АННОТАЦИЯ}

Целью статьи является раскрытие творчества Фердинанда Эдуардовича Рущица, мастера пейзажной живописи. Эта тема недостаточно изучена и актуальна. Историко-биографический метод послужил в исследовании основным; кроме того, использовались элементы искусствоведческих методов в анализе картин. В результате автор приходит к выводу о том, что творчество Фердинанда Рущица обнаруживает влияние И.И. Шишкина, а затем и А.И. Куинджи. Ф. Рущиц был не только тесно связан с молодой русской пейзажной школой под руководством А.И. Куинджи в 1898-1905 годах, но и являлся одним из тех, кто ее формировал и придавал ей свое лицо. Динамика художника от ранних работ к более поздним, его колористический талант замечательно проявился в таких произведениях, как «Земля», «Мельница», «У костела», «Старые яблони» и других. Его произведениям присущи тонкое сочетание цвета и точная композиционная завершенность. Первым из белорусских живописцев, заложившим основы национальной школы пейзажной живописи, он смог раскрыть через красоту родной природы повседневную жизнь своего народа.

\section{КЛЮЧЕВЫЕ СЛОВА:}

Живопись; изобразительное искусство; Фердинанд Рущиц; пейзажи.

\section{ABSTRACT}

The purpose of this article is to reveal the work of the master of the extraordinary expressive landscape Ferdynand Ruszczyc. Because of the lack of knowledge of the topic, this goal seems relevant. The historical-biographical method served as the main method of research here. The author concludes that the work of Ferdynand Ruszczyc reveals the influence of Ivan Shishkin, and then Arkhip Kuindzhi. He was not only closely associated with the young Russian landscape school under the leadership of A.I. Kuindzhi in 1898-1905, but was also one of those who formed it and gave it its own unique identity. The dynamics of the artist from early works to later ones, his coloristic talent was remarkably manifested in such works as "Earth", "Mill", "Near the Church", "Old Apple Trees", etc. His works are characterized by a subtle combination of color and precise compositional completeness. The first Belarusian painter to lay the foundations of the national school of landscape painting, he was able to reveal the daily life of his people through the beauty of his native nature.

\section{KEYWORDS:}

Painting; fine arts; Ferdynand Ruszczyc; landscapes. 


\section{Введение}

Творчество мастера необыкновенно выразительного пейзажа Фердинанда Эдуардовича Рущица недостаточно изучено современными исследователями и представляет сегодня значительный интерес. Вопрос о национальной принадлежности Ф. Рущица чрезвычайно непростой. В белорусской искусствоведческой литературе его имя упоминается очень редко. Советские и польские искусствоведы рассматривают его творчество как яркую страницу польской национальной культуры. Так, искусствовед и коллекционер Б.Д. Сурис писал: «В этих ранних, наиболее ценных произведениях Ф. Рущица, прочно вошедших в золотой фонд польской живописи и продолжающих лучшие ее традиции, несомненно, отразились и творчески преломленные традиции русской реалистической школы» [15, с. 63]. Архивные материалы, воспоминания современников, знавших Ф. Рущица лично, а также изучение его живописи дают повод высказать новую точку зрения на творчество художника, который был не только польским, но и белорусским живописцем [2; 14]. Постепенно, благодаря таким исследователям его творчества, как Л.Н. Дробов [5], М.С. Кацер [7], Л.И. Тананаева [16; 17], В.С. Манин [12], Т.А. Колесникова [8; 9; 10; 11], Т.В. Бубич [3], В.И. Прокопцов [13], В.А. Шуршина [19] и др. [1; 18], к нам возвращается имя выдающегося белорусского художника, его произведения. Наиболее интересной, на наш взгляд, представляется его пейзажная живопись, которой и посвящена данная статья. В работе используются историкобиографический и элементы ряда искусствоведческих методов.

\section{Обсуждение}

Судьба Фердинанда Рущица - словно зеркало, в котором Белоруссия (совр. Республика Беларусь) конца XIX - первых десятилетий XX века, упорно ищущая свое место на географической карте мира, как птица Феникс, возрождающаяся, казалось бы, из небытия, могла увидеть себя. Впрочем, если сквозь это зеркало заглянуть дальше в глубь веков, куда ведет своими корнями род Рущицев, то и там можно найти немало интересного.

Далекие предки Фердинанда Рущица были православными шляхтичами, потом, во время упадка Великого княжества Литовского и расцвета Речи Посполитой приняли католическую веру. В хозяйственных делах они разбирались неплохо. По крайней мере, известно, что начиная с XVI века они могли позволить себе приобретать имения, а дольше всего, около двух веков, жили в имении Мокряны, что в 50 километрах от Кобрина. В 1836 году адвокат Фердинанд Рущиц, дед знаменитого художника, перевозит семью в купленное на аукционе и некогда принадлежавшее Богдану Сапеге имение
Богданов, что было недалеко от Воложина. По наследству имение переходит к среднему сыну Эдуарду и его жене - Анне Маргарите Альвине Мунх, по происхождению датчанке. В их семье, где уже было четыре дочери, 10 декабря 1870 года и рождается Фердинанд Рущиц. В 13-летнем возрасте отец отдает его в минскую классическую гимназию, а затем, в 1890 году, несмотря на уговоры гимназического педагога Кузьмы Яковлевича Ермакова, настаивающего на том, что у юноши большие способности к рисованию,- - заставляет его поступать на юридический факультет Петербургского университета. Во время учебы Фердинанд посещал выставки и музеи. Л.И. Тананаева в своей работе о творчестве этого видного живописца, графика, деятеля культуры приводит ряд важных биографических сведений: «Фердинанд Рущиц поступил в Академию художеств сначала вольнослушателем, а с 1894 года стал учеником И.И. Шишкина. Шишкин отнесся к нему чрезвычайно внимательно - в дневнике молодого Рущица, который он вел с юности (с 1894 г. регулярно, и впоследствии не изменял и не переделывал), сохранилось много записей, с симпатией обращенных к этому первому учителю. Шишкин представлял себе будущее молодого художника как мариниста типа Айвазовского, и обе поездки Рущица в Крым в 1894 и 1895 гг. были подсказаны ему профессором» [17, с. 204]'.

Однако, отмечает затем автор, «В дальнейшем стало ясно, что такой путь неприемлем для юноши, очень чутко отзывавшегося на новые настроения и духовные искания своего поколения. После одного из посещений И.И. Шишкина, при том, что он его очень хвалил, Рущиц записывает с горечью: "О, боже мой! Неужели они никогда не поймут, что я могу быть не только прилежным адептом искусства, но могу дать и что-то свое, новое! Неужели и впрямь у меня "столько ошибок", что музыкальность, которую я в себе чувствую, не заметна в моих картинах? Я чувствую, что у меня есть дар божий, что тлеет в моей душе искра с алтаря красоты, но когда же я найду такую, понятную всем, оправу, чтобы через ее посредство и другим светила эта искра?". Очень характерно, что запись кончается такими словами: "В эти дни я читал письма Васильева к Крамскому, а предисловие - даже два раза. Я себя не сравниваю с Васильевым, но когда же я найду такого учителя-друга, который поймет меня своим сердцем?"» [17, с. 204]. Эти записи относятся к 1894 г., а годом позже, «после ухода Шишкина из Академии, Рущиц с группой других его учеников перешел в мастерскую Куинджи. Молодые люди оказались в окружении тесной, сплоченной компании “куинджистов", и некоторое время Рущиц, склонный к замкнутости и приступам неуверенности в своих силах, тяжело это переживал. Однако атмосфера мастерской быстро 
1. Ф.Э. Рущиц. Весна.

1897.

Холст, масло.

$152 \times 103$.

Государственная

Третьяковская галерея

\section{2. Ф.Э. Рущиц.}

Земля.

1898.

Холст, масло.

$171 \times 219$.

Национальный

музей в Варшаве.

Фото: artmuseum.by

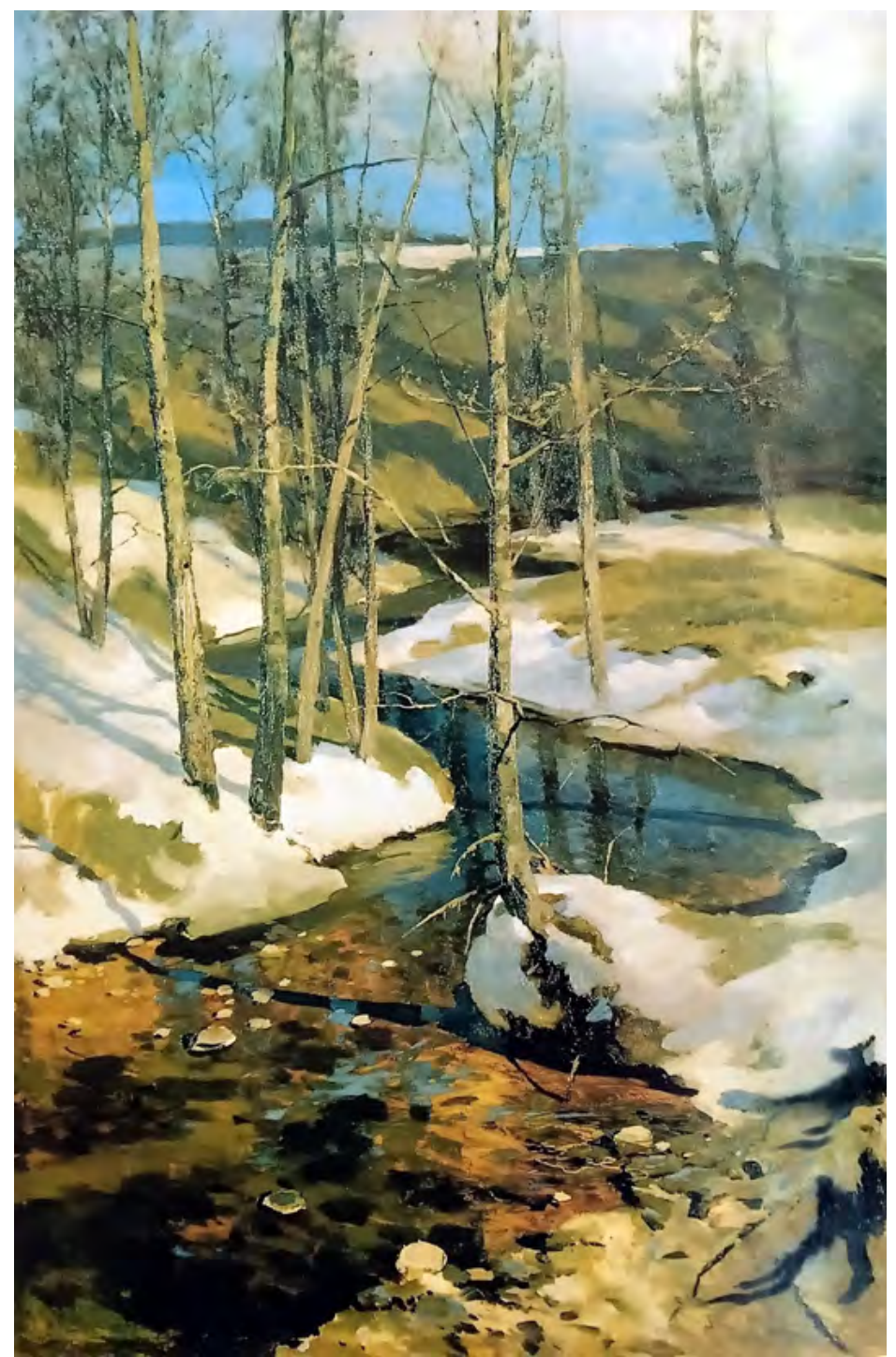

подчинила "шишкинцев" себе, а Рущиц обрел того идеального учителя, о котором тосковал еще год назад. О мастерской Куинджи написано очень много, и нет необходимости повторять, как именно работал Архип Иванович с учениками. Скажем только, что для тех, кто изучает эту группу художников, записки Рущица могут быть очень интересны. Он описывает визиты Куинджи к себе в мастерскую, скрупулезно фиксирует каждое его слово; дневник пестрит замечаниями учителя. Достаточно похвалы, оброненной Куинджи, чтобы Рущиц вернулся к брошенной, было, работе» [17, с. 205].

Интересно, что «Впоследствии, живя в семье и удивляясь точности суждений своей матери об искусстве, Ф. Рущиц называл ее "своим Куинджи"» [16, с. 81]. «В 1897 году Ф. Рущиц представил на дипломную выставку три картины - "Вечерняя звезда", "Тритоны" и "Весна" - и успешно окончил учебу в Академии художеств, получив звание художника» [13]. Когда Фердинанд заканчивает учебу, его отец Эдуард Рущиц, считавший, что на рисование не проживешь, был очень доволен, что одну из дипломных работ сына, картину

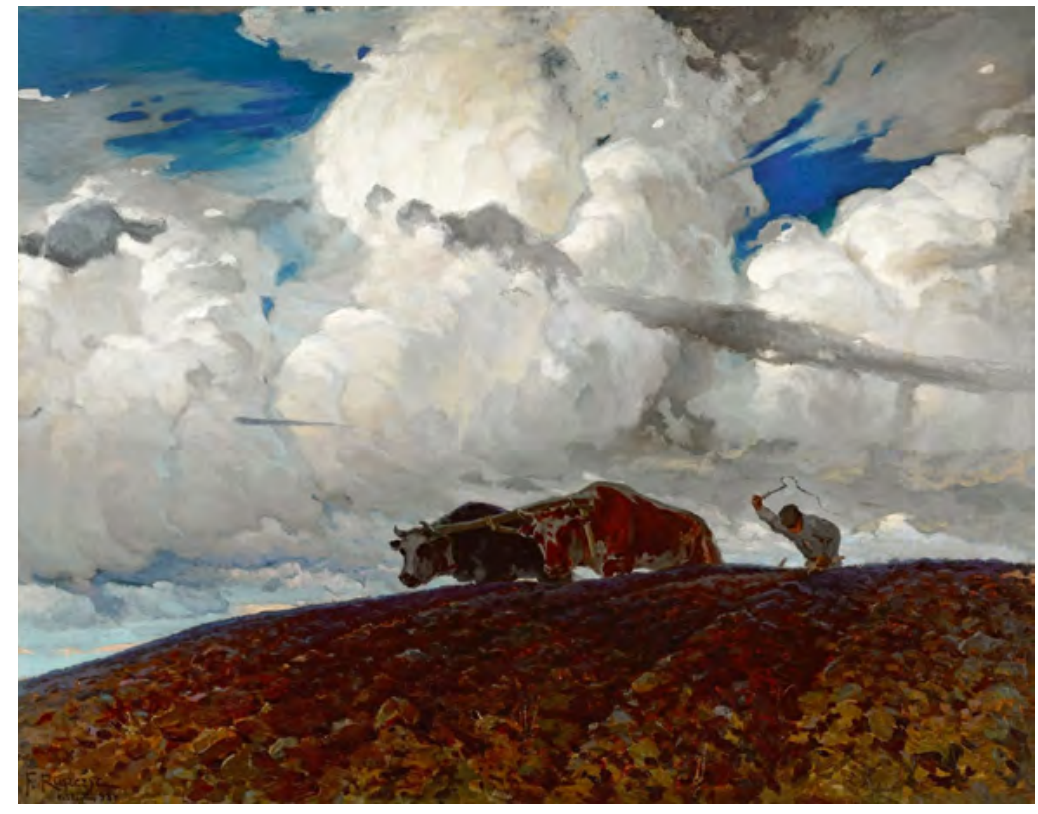

«Весна» приобретает сам П.М. Третьяков (рис. 1). Эта картина «воспринималась многими как новое слово в пейзаже... Рядом с нею, в таких же поисках и сомнениях, рождались первые крупные работы коллег: Рылов выставил вместе с Рущицем конкурсную картину (нападение татар на русское селение, названное им, по совету Рериха, "Набежали злы татаровья"), Н.К. Рерих искал свои пути рядом с работами коллег на той же выставке висел его "Гонец". Эти полотна были также куплены П.М. Третьяковым. Успех молодых мастеров был отпразднован всей мастерской вполне достойным образом...» [17, с. 206].

Т.А. Колесникова в исследовании, посвященном символике в живописных образах художника, отмечает, что «источником вдохновения для создания почти всех пейзажей Рущица, за исключением ранних фантастических полотен "Вечерняя звезда" (1897) и “Тритоны” (1897), написанных под влиянием Беклина и Штука, стало родовое имение Богданово. Вместе с тем реальность Рущиц воспринимал обостренно, постоянно отыскивая в ней духовные тайны. Самые простые явления наполнялись в его картинах таинственным значением» [11, с. 57]. Самую главную свою картину «Земля» (1898) Ф. Рущиц пишет именно в Богданове (рис. 2). «16 сентября в своем богдановском дневнике он описал начало работы над картиной так: “Набросал углем "Землю”. Пользуясь чудесной погодой, с мамой и с папой мы идем на поле, где копают картофель. Паутина, теплый и ясный день без ветра. На голубизне неба горят желтые листья деревьев"» [3, с. 77]. На картине, принесшей известность 28-летнему художнику, мы видим простой крестьянский мотив, доведенный до большой эмоциональной напряженности. 


\section{Искусство Евразии}

\section{№1 (20) 2021 elSSN 2518-7767}

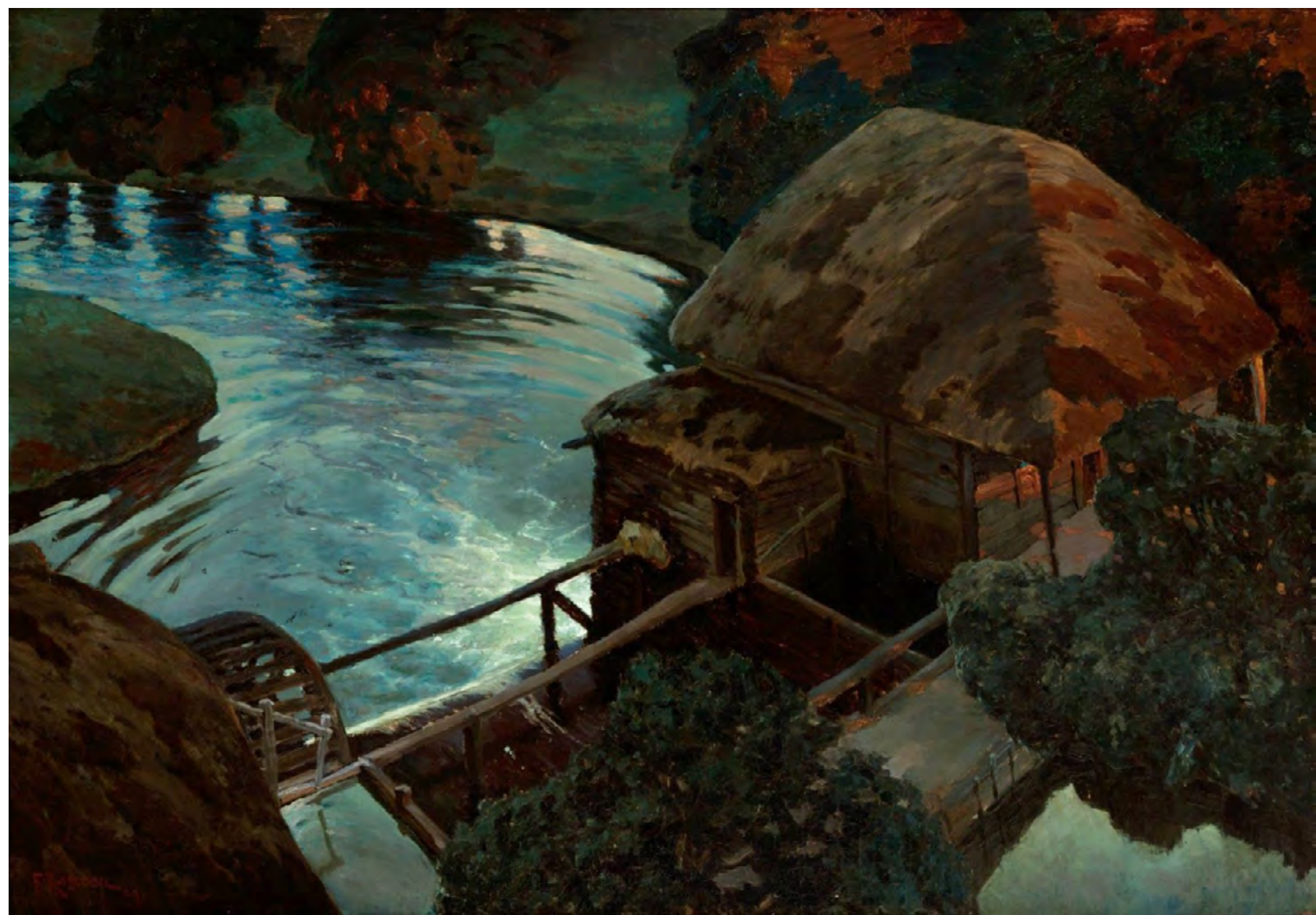

Никто прежде не рисовал таких выразительных огромных облаков, которые словно бы осели на плечи пахарю, занятому своей работой. В этом произведении необыкновенно близко сошлись земля и небо. «На творческом подъеме автором создаются в Богданове и другие замечательные произведения: “Мельница” (1898), “Крево” (1898), "Последний снег” (1898-1899), "У костела" (1899), “Баллада" (1899-1900) и др.» [13]. С высоты птичьего полета художник смотрит на природу в картине «Мельница» (рис. 3). Благодаря такому приему, он изображает только землю, исключая в целом небо. Мельница и окружающие предметы показаны в непривычном для зрителя ракурсе. Колорит картины очень напоминает значительные украинские пейзажи А.И. Куинджи с их яркой красочностью и декоративностью. Ф. Рущиц, по-видимому, стремился создать нечто подобное и на белорусском материале. Он изображает ручеек с деревянной плотиной и с большим деревянным колесом, приводящим в движение мельничные жернова. Здание мельницы типично для белорусского пейзажа. Оно приземистое, с поросшей мхом соломенной крышей. Все предметы в пейзаже окрашены в красноватые и зеленоватые тона. Удивительное сочетание красок придает очарование этому красивому уголку белорусской природы. В отличие от ранее рассмотренных работ художника общее настроение пейзажа здесь бодрое, приподнятое. Во всем ощущается своеобразная лирика и романтика. Неслучайно русский историк В.В. Стасов называл «Мельницу» Ф. Рущица «великолепной» и «оригинальной» картиной [16, с. 85]. Добавим здесь еще, что С.Т. Морозов приобрел эту картину в год ее создания.

В работе «У костела» (1899), хранящейся в Национальном художественном музее Республики Беларусь, мы видим фасад Богдановского деревянного костела Св. Михаила Архангела с отдельно поставленной звонницей (рис. 4). Перед ним в ожидании толпятся люди, несущие в храм свои печали. На сучьях деревьев - грачи, на необычном небе - экспрессивные бело-розовые облака, а вдали виднеются серые холмы. Эту грустную картину белорусские искусствоведы считают одной из самых значимых в творческом наследии Ф. Рущица, поскольку спектр мотивов здесь очень широк. «Фигуры людей вливаются в пейзаж, конкретизируя общий драматический, даже трагедийный образ, обнаруживая духовность природы» $[11$, c. 58$]$.
3. Ф.Э. Рущиц.

\section{Мельница.}

1898.

Холст, масло.

$112 \times 162$

Национальный музей в Кракове Фото: artmuseum.by 
4. Ф.Э. Рущиц. У костела.

1899.

Холст, масло.

$103,7 \times 78$.

Национальный

художественный музей

Республики Беларусь.

Фото: artmuseum.by

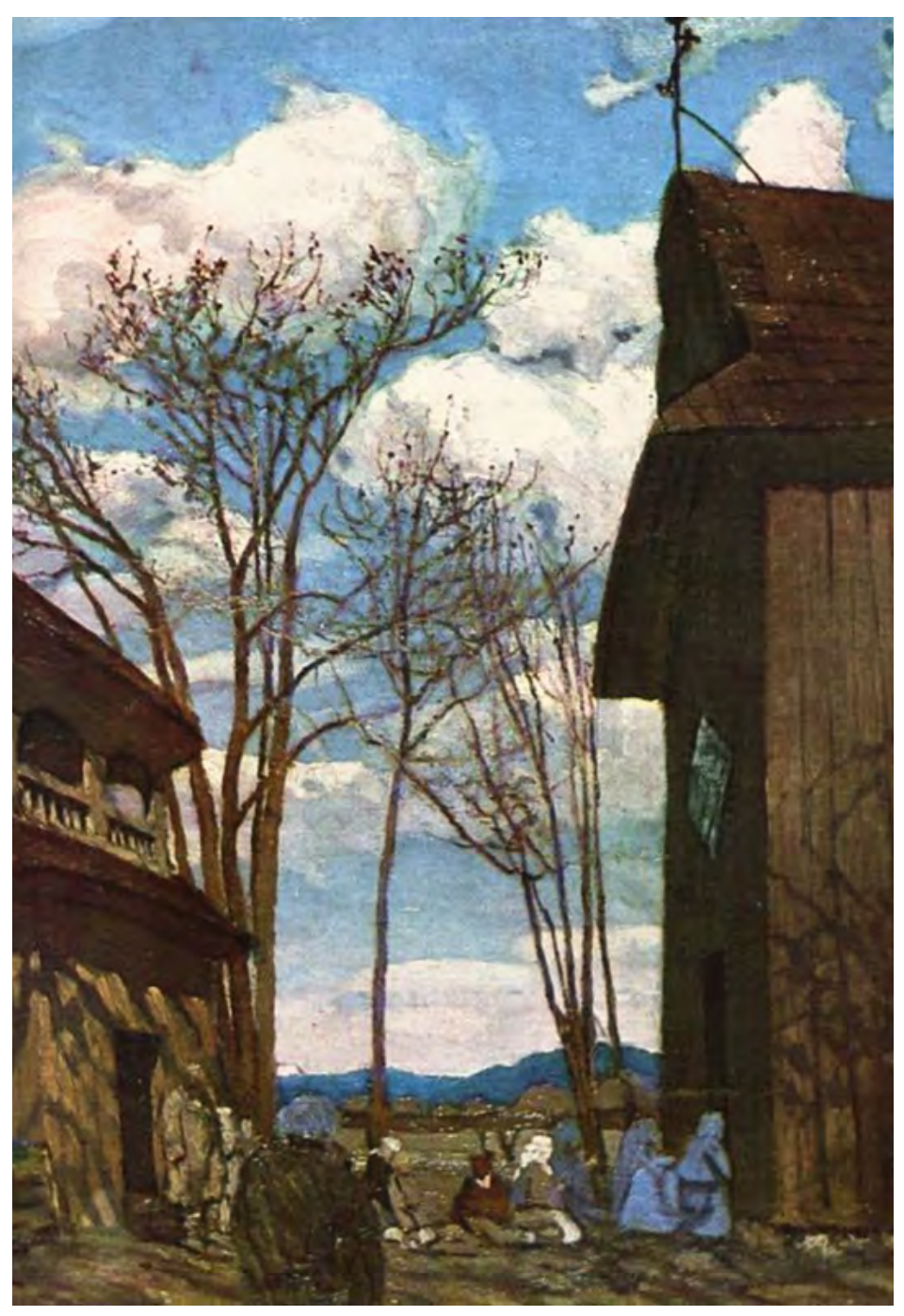

Т.В. Бубич и М.С. Шестернев отмечают: «Труднее всего ему далась работа над картиной: "Старые яблони" (1900), на которой деревья напоминают людей-мучеников» [3, с. 79]. При взгляде на эту работу невольно возникает предчувствие надвигающейся катастрофы (рис. 5). Так и было на самом деле. На шестьдесят третьем году жизни Ф. Рущиц перенес инсульт, у него была парализована правая половина тела, он совсем не мог говорить. Благодаря усилиям своих близких - жены и дочери, он научился рисовать левой рукой и не сдавался, создав много карандашных зарисовок («Семья художника», «Деревья над водой» и др.). «Изогнутые стволы, переплетенные ветви деревьев напоминают старческие руки пожилых людей, которые провели многие годы в тяжелой работе» [3, с. 80], они выделяются светлыми тонкими, изогнутыми линиями на темном зеленом фоне травы и неба. В октябре 1900 года картина «Старые яблони» была закончена, а спустя двадцать девять лет ее приобрел польский Сенат для своего парадного зала. Сегодня картина входит в собрание Национального музея в Варшаве.

Ф. Рущиц в своих произведениях смог также передать через родные пейзажи драматизм жизни тех бедных людей, которые были вынуждены искать счастья на чужбине. Так, в 1902 году была создана картина «Эмигранты» (рис. 6). Анализируя это полотно, Т.В. Бубич и М.С. Шестернев обращают внимание на ключевые образы: «Мы здесь видим, как по богдановской аллее в осенний час идут с вещами переселенцы. И холодный, беспощадный ветер гонит их с этой земли так же, как и пожелтевшие листья с высоких берез. Каждый из них хоть на мгновение бросает взгляд в сторону родного дома и не оставляет веры в свое возвращение» [3, с. 81].

К этому времени относится следующий этап творческой биографии художника: «Через несколько лет после окончания Академии, в 1902 году Рущиц был принят в "Мир искусства" как постоянный член, участник выставок. Он был также избран вместе с О.Э. Бразом в ревизионную комиссию товарищества и, таким образом, связи его с художественной жизнью России, ее наиболее активными в те годы художественными группировками, усилились. Он выставляется на Весенних выставках 1899 и 1900 гг., на выставках "Мира искусства", пишет свои лучшие картины "Ручей (Лесной ручей)", "Земля»", "Мельница", "Последний снег", "Зимняя сказка (Зимняя история)"» [17, с. 208] (рис. 7, 8). Работа «Зимняя сказка (Зимняя история)» была написана в 1904 году. В ней ощущается воздействие необыкновенного выразительного стиля модерн: декоративность, мягкость и плавность линий, тихая красота белорусского зимнего пейзажа. Кажется, что всё в зимнем лесу запорошено снегом, покрыто инеем и схвачено морозом. Только маленькое озерцо осталось не замерзшим, и перед ним таинственно склонили свои заснеженные ветви деревья.

«С 1904 года Ф.Э. Рущиц постоянно живет и работает в Польше, возглавляет кафедру живописи в Варшавском училище изящных искусств, а с 1907 г.- в Краковской Академии художеств, входит в общество: "Штука" (“Искусство”)» [17, с. 202]. Динамика художника от ранних работ к более поздним, его колористический талант замечательно проявился и в этюде «Зима» (1908). Изумрудами, самоцветами переливаются на солнце снежинки. Занесенные снегом ветви старых елей, переплетаясь, создают причудливый узор, напоминающий кружева искуснейших мастериц. Во всей живописной ткани этюда чувствуется неповторимое очарование белорусской снежной зимы. Еще в 1898 году художник писал: «Мы видим красоту других стран, восхищаемся ими, но любим только свою, чувствуем, что она принадлежит нам, а мы ей» [3, с. 79].

Жизнь и вся дальнейшая деятельность Ф. Рущица были прочно связаны с Вильно, в Котором ОН активно работал с 1909 года (виленскую школу он возглавлял до 1934 года). «В вильненский период 


\section{Искусство Евразии}

\section{№1 (20) 2021 elSSN 2518-7767}

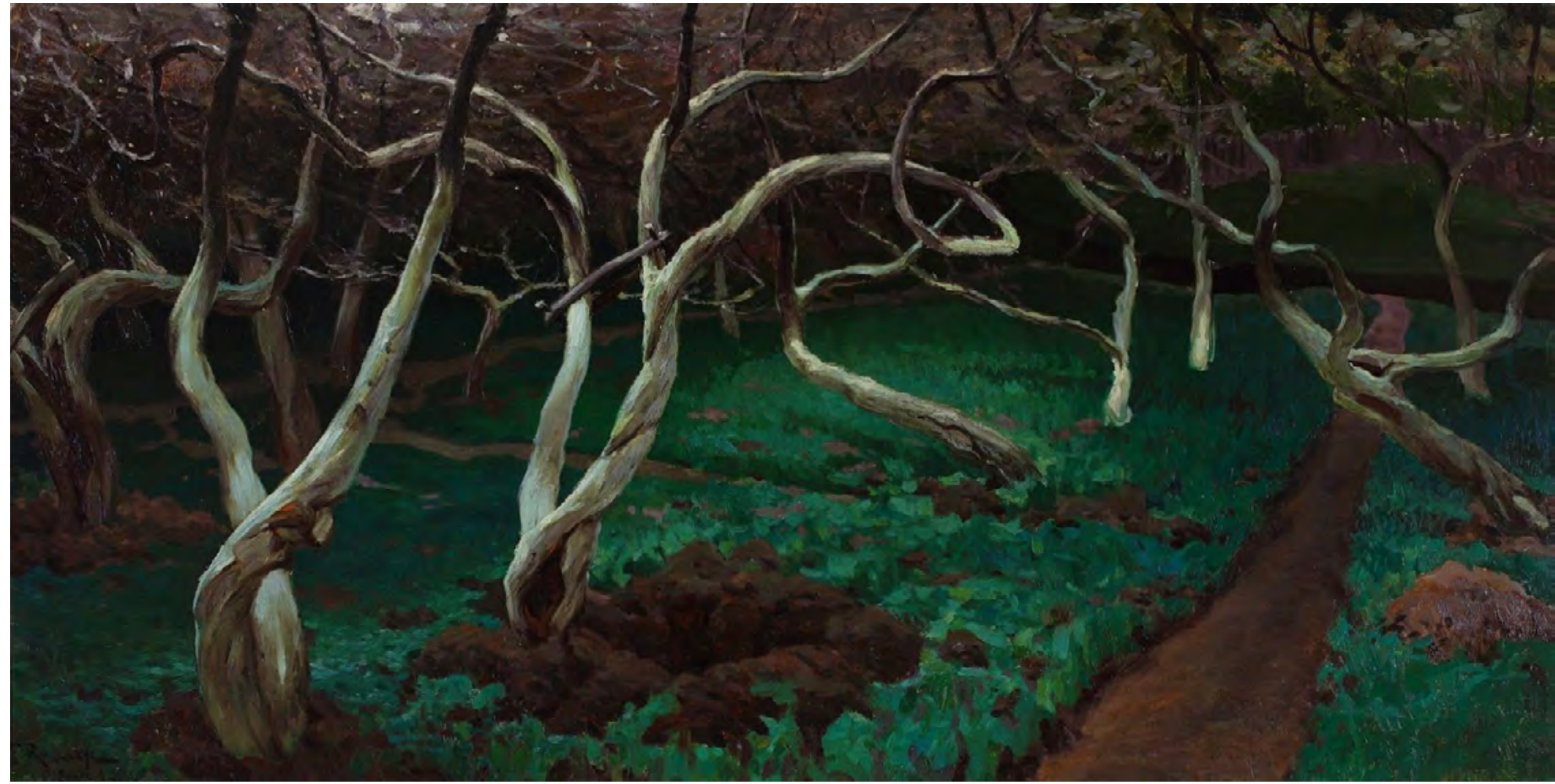

5. Ф.Э. Рущиц.

\section{Старые яблони.}

1900.

Холст, масло.

$85 \times 165$.

Национальный

музей в Варшаве.

Фото: artmuseum.by

\section{6. Ф.Э. Рущиц.}

\section{Эмигранты.}

1902.

Холст, масло.

$88 \times 168$.

Литовский

художественный музей,

г. Вильнюс.

Фото: tg-m.ru

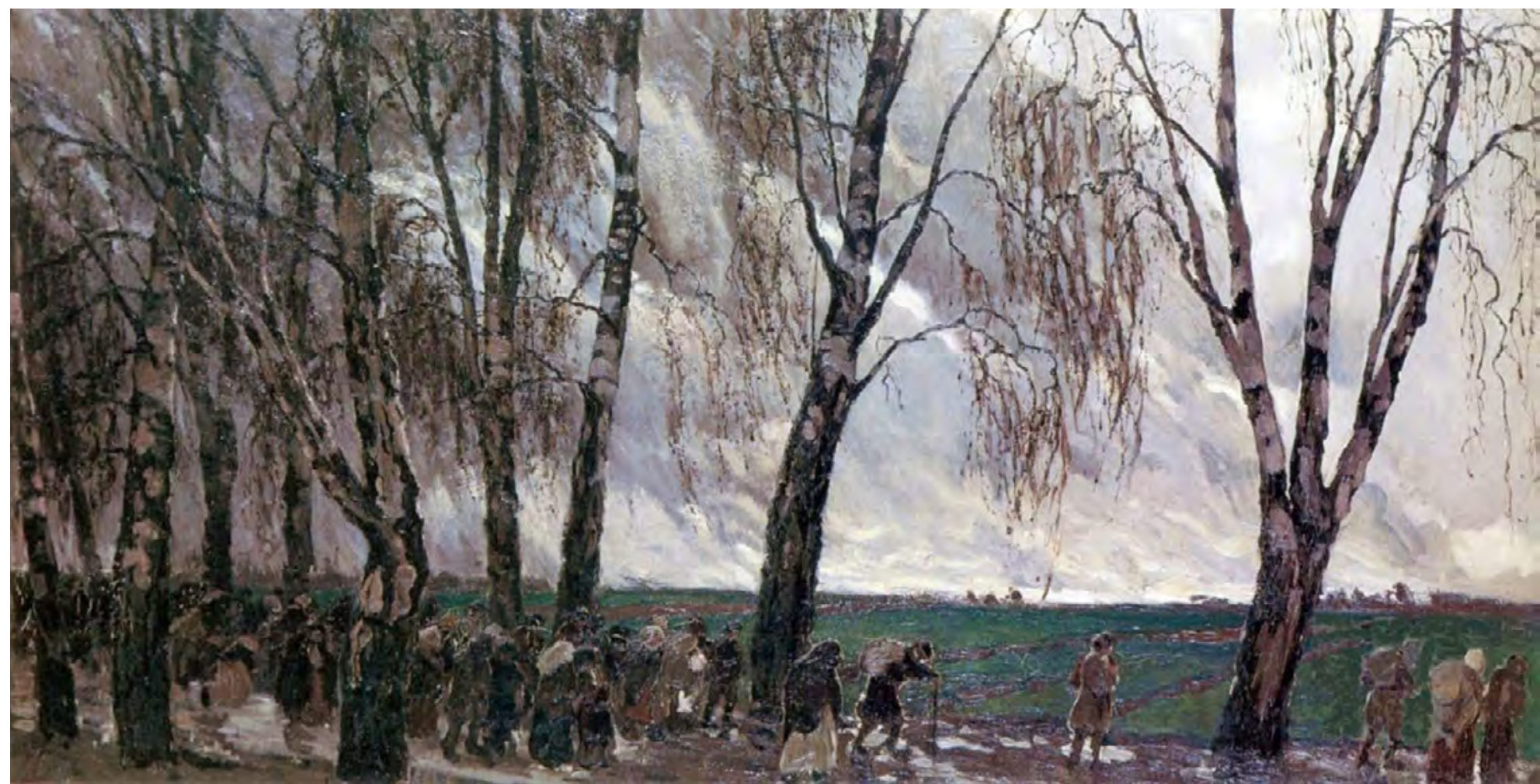

Рущиц очень много занимался театральной декорацией, особенно удачны были его оформления польских пьес, например “Лиллы Венеды" Словацкого, где действие переносится в доисторическое прошлое Польши. Здесь, в эскизах декораций и в моделях костюмов, нетрудно вновь заметить общность с работами русских художников, в том числе со сценографией Рериха, также обращавшегося (и в тот же период) к доисторическим временам» [17, с. 211].

«В 1910 году он сотрудничал с городским театром "Ksiqzg nieugiety"; офрормил литературный альманах Ю. Словацкого "Восіаnу"; иллюстрировал программу Виленского театра и книгу Й. Вержиньского "Воспоминания великих дней. Грюнвальд. 1410-1910”. Вместе с тем Ф. Рущиц не оставлял и художественной деятельности. Так, 12 марта 1911 года организовал в Минске свою первую персональную выставку, где представил не менее выразительную, чем его пейзажи, картину «Nec mergitur» (1904-1905)» 13] (рис. 9). По мнению искусствоведа Т.А. Колесниковой, «корабль - символ путешествия по жизни у древних 


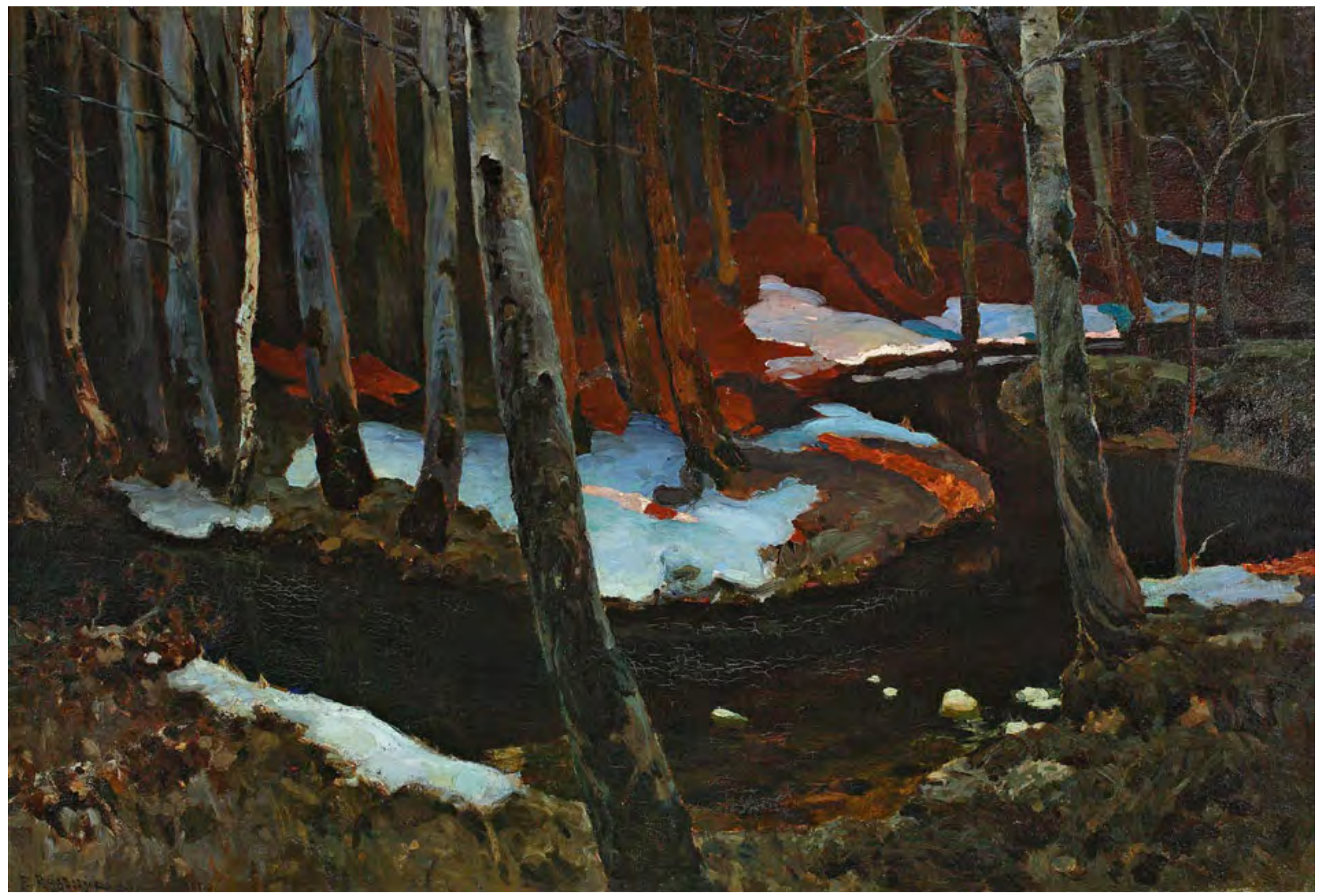

7. Ф.Э. Рущиц.

Ручей (Лесной ручей). 1900.

Холст, масло.

Национальный музей в Варшаве.

Фото: tg-m.ru

\section{8. Ф.Э. Рущиц.}

\section{Зимняя сказка}

(Зимняя история).

\section{4.}

Холст, масло.

$132 \times 159$

Национальный музей в Кракове.

Фото: artmuseum.by народов - в "Nec mergitur" олицетворяет современную художнику Польшу, ее многострадальную судьбу. Драматическая интонация в этом произведении связана с темой рока, предзнаменования» [11, c. 60].

Фердинанд Рущиц «в конце 1911 года вместе с Вацлавом Студницким, будущим директором Государственного виленского архива, издал первый номер “Tygodnik Wilenski”, посвященный художественно-культурным событиям края и его связям с Польшей. В начале 1912 года он организовал представление "В мире сказок и развлечений”, создал для него эскизы костюмов; сделал обложку журнала "Литва и Русь" в память о Владиславе Сырокомле и оформил его многочисленными изображениями; издал альбом "Вильно через века" с репродукциями Франтишка Смуглевича и собственными рисунками» [13]. Работая

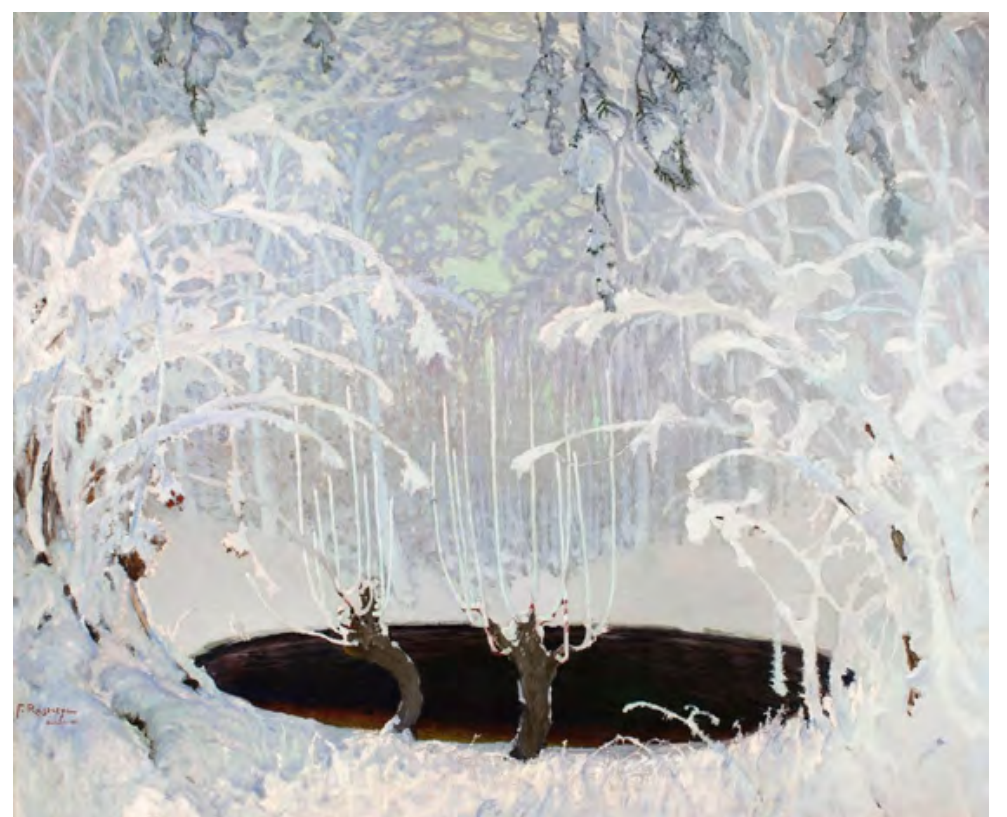




\section{Искусство Евразии}

№1 (20) 2021 elSSN 2518-7767

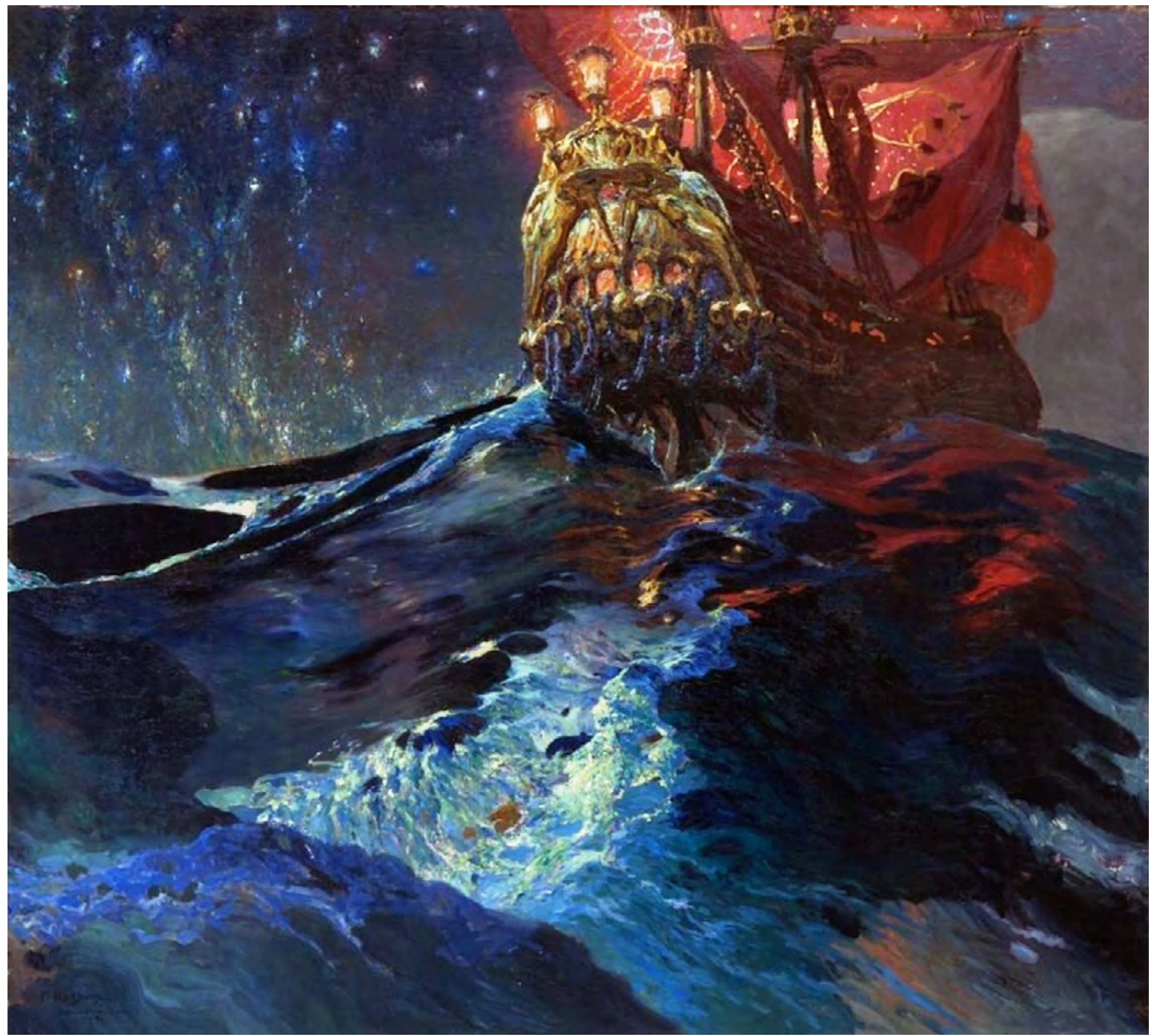

9. Ф.Э. Рущиц.

Nec mergitur.

1904-1905.

Холст, масло.

$219 \times 203$.

Литовский

художественный музей.

Фото: artmuseum.by

над сохранением памятников прошлого, Ф. Рущиц принял участие в учреждении «Городского архива фотографии» в городской управе, собравшего «под руководством замечательного фотографа и друга Яна Булгака... фотоснимки памятников архитектуры» [19, с. 27].

Как театральный художник Ф. Рущиц «работал над. . постановками не только в Вильно. По заказу директора Польского театра в Варшаве Арнольда Шифмана он создавал эскизы декораций и костюмов к постановке "Balladyna" Юлиуша Словацкого, ставшей настоящим успехом художника и вошедшей в историю польской сценографии» [13].

Следующая веха в жизни художника связана с переездом обратно в Богданово в конце лета 1915 года, и «в течение 1916-1919 годов он жил и работал в своем имении, перенес там тяжелые годы военной оккупации. 19 апреля 1919 года вернулся в Вильно, где сразу же активно включился в творческую и общественную деятельность: приступил к организации Виленского университета, стал основателем и деканом факультета изящных искусств, профессором» [13]. Не оставляя общественную деятельность, «в 1920-1930-х годах Ф. Рущиц являлся председателем Комиссии по охране памятников древностей, много ездил по Беларуси (где тогда проживал), делал зарисовки старинных замков и их руин, оформлял книги и журналы. В 1921 году Ф. Рущиц стал организатором первой официальной выставки польских художников в Гран-Пале в Париже. В связи с этим он был награжден Орденом Почетного легиона» 
[19, с. 27]. В 1932 году Ф. Рущиц тяжело заболел и вследствие этого не мог говорить, а также писать правой рукой. Он поселился в Богданове и продолжал делать зарисовки.

По выходе Ф. Рущица на пенсию в 1935 году художнику было присвоено звание почетного профессора Университета Стесана Батория. «Умер Фердинанд Рущиц 30 октября 1936 года. Его картины можно увидеть в музеях и частных коллекциях Польши, Литвы, Белоруссии, России (в музеях ГТГ, ГМИИ им. А.С. Пушкина)» [19, с. 27].

\section{Заключение и выводы}

Творчество живописца, графика, карикатуриста, педагога, общественного деятеля Фердинанда Рущица считают своим белорусы, литовцы, поляки, французы. Очень высоко ценил его Н.К. Рерих, который считал его корифеем польского искусства. Как художник Ф. Рущиц сначала формировался в мастерской И.И. Шишкина, а затем и А.И. Куинджи. Он был не только в 1898-1905 годах тесно связан с молодой русской пейзажной школой под руководством А.И. Куинджи, но и «являлся одним из тех, кто ее формировал и придавал ей свое лицо» [17]. Большой эмоциональной силой отличаются такие произведения, как «Земля», «Мельница», «У костела», «Старые яблони» и др. Не менее выразительной, чем его пейзажи, была картина «Nec mergitur» (1904-1905). Ее он представил на своей первой персональной выставке в Минске, которая была организована 12 марта 1911 года. Произведениям Ф. Рущица присущи тонкое сочетание цвета и точная композиционная завершенность. Первым из белорусских живописцев, заложившим основы национальной школы пейзажной живописи, он смог раскрыть через красоту родной природы повседневную жизнь своего народа.

\section{Примечания}

1. Методы преподавания И.И. Шишкина в пейзажной мастерской Императорской Академии художеств исследованы А.А. Грибановой [4]. 


\section{Литература}

1. Бадак А. Фердинанд Рущиц (1870-1936) // Неман. 2009. № 9. С. 2.

2. Белый А.В. Земля Фердинанда Рущица // Деды: дайджест публикаций о белорусской истории. Вып. 3 / сост., науч. ред.: А.Е. Тарас. Минск: Харвест, 2010. С. 190-195.

3. Бубич Т.В., Шестернев М.С. Творчество Ф. Рущица и К. Каганца в контексте стиля модерн // Модерн в России. Накануне перемен: сборник научных статей XXIII Царскосельской конференции / Гос. музей-заповедник «Царское село».

Санкт-Петербург: Серебряный век, 2017. С. 74-83.

4. Грибанова А.А. Педагогическая деятельность И.И. Шишкина в Императорской Академии художеств // Декоративное искусство и предметно-пространственная среда: вестник МГХПА. 2015. № 3. С. 150-159.

5. Дробов Л.Н. Живопись Белоруссии XIX - начала XX в. / под ред. А.И. Мальдиса. Минск: Вышэйш. школа, 1974. 336 с. 6. Иван Иванович Шишкин: переписка. Дневник. Современники о художнике / сост., вступит. ст., примеч. И.Н. Шуваловой. Ленинград: Искусство, 1978. 463 с.

7. Кацер М.С. Изобразительное искусство Белоруссии дооктябрьского периода: очерки / АН БССР; Ин-т искусствоведения, этнографии и фольклора. Минск: Наука и техника, 1969. 204 с.

8. Колесникова Т.А. Национальная идея и пейзаж // Российская культура глазами молодых ученых: Сборник трудов.

Вып. 13. Санкт-Петербург: Культ-Информ-Пресс, 2003. С. 132-143.

9. Колесникова Т.А. Национально-романтический пейзаж конца XIX - начала XX века в творчестве Фердинанда Рущица: авторесрерат дис. ... канд. искусствоведения. Санкт-Петербург, 2005. 24 с.

10. Колесникова Т.А. Романтические драмы Юлиуша Словацкого в художественной интерпретации Фердинанда Рущица // Проблемы художественного синтеза: материалы конф. аспирантов Рос. ин-та истории искусств, 19 и 21 нояб. 2001 г. / сост. и ред. А.А. Кириллов. Санкт-Петербург: ГНИУК РИИИ, 2004. С. 75-78.

11. Колесникова Т.А. Символика в живописных образах Фердинанда Рущица // Символ, символическое, символизация в искусстве и культуре. Проблемы языка искусства: материалы конф. аспирантов Рос. ин-та истории искусств / сост. и ред. А.А. Кириллов. Санкт-Петербург: ГНИУК РИИИ, 2001. С. 57-61.

12. Манин В.С. А.И. Куинджи // Архип Иванович Куинджи и его школа: альбом / авт. текста и сост. В.С. Манин. Ленинград: Художник РСФСР, 1987. 215 с.

13. Прокопцов В.И. Небо и земля Фердинанда Рущица // Третьяковская галерея. 2018. № 3. С. 138-155.

URL: https://www.tg-m.ru/articles/3-2018-60/nebo-i-zemlya-ferdinanda-rushchitsa (дата обращения: 16.01.2021).

14. Рерих Н.К. Рущиц-Вроблевский // Рерих Н.К. Листы дневника. Т. 3: (1942-1947). Москва: МЦР, 2002. С. 599.

15. Сурис Б.Д. Из истории связей польского изобразительного искусства с русской художественной культурой // Искусство. 1954. №1. С. 56-66.

16. Тананаева Л.И. К проблематике творчества Фендинанда Рущица // Художественные процессы в русском и польском искусстве XIX - начала XX века: сборник статей / под ред. Е.А. Борисовой и др. Москва: Наука, 1977. С. 69-90.

17. Тананаева Л.И. О некоторых аспектах творчества Фердинанда Рущица // Вестник славянских культур. 2015. № 3 (37). C. 194-214.

18. Фердинанд Рущиц: виртуальная выставка к 150-летию со дня рождения // Национальный художественный музей Республики Беларусь [Официальный сайт]. URL: https://www.artmuseum.by/ru/vyst/virt/ferdinand-rushhicz.-virtualnaya-vyistavka-k-150-letiyuso-dnya-rozhdeniya.html (дата обращения: 26.01.2021).

19. Шуршина В.А. Мастерская А.И. Куинджи. Фердинанд Рущиц // Н.К. Рерих и Литва: альбом выставки, 14 декабря 2018 24 марта 2019 / сост. В.А. Шуршина. Санкт-Петербург: Санкт-Петербургский государственный музей-институт семьи Рерихов, 2019. C. 26-31.

ИНФОРМАЦИЯ ОБ АВТОРЕ: Филиппова Ольга Николаевна - искусствовед, заведующая научным архивом, Политехнический музей, г. Москва, Российская Федерация. E-mail: iscusstvo0891@mail.ru

ABOUT AUTHOR: Filippova, Olga Nikolaevna - Head of the scientific archive, the Polytechnic Museum, Moscow, Russian Federation. E-mail: iscusstvo0891@mail.ru. 


\section{References}

1. Badak A. Ferdinand Rushchits (1870-1936) [Ferdynand Ruszczyc (1870-1936)]. Neman, 2009, No. 9, pp. 2. (In Russian). 2. Bely A.V. Zemlya Ferdinanda Rushchitsa [The land of Ferdynand Ruszczyc]. Taras A.E. (comp.). Dedy: daidzhest publikatsii o belorusskoi istorii. Vyp. 3 [Grandfathers: a digest of publications on Belarusian history. Issue 3]. Minsk, Harvest Bubl., 2010, pp. 190-195. (In Russian).

3. Bubich T.V., Shesternev M.S. Tvorchestvo F. Rushchitsa i K. Kagantsa v kontekste stilya modern [The works of F. Ruszczyc and K. Kagants in the context of the modern style]. Modern v Rossii. Nakanune peremen [Modern in Russia. On the eve of changes: Conference materials]. St. Petersburg, Serebryanyi vek Bubl., 2017, pp. 74-83. (In Russian).

4. Gribanova A.A. Pedagogicheskaya deyatel'nost' I.I. Shishkina v Imperatorskoi Akademii khudozhestv [The pedagogical activity of I.I. Shishkin at the Imperial Academy of Arts]. Dekorativnoe iskusstvo i predmetno-prostranstvennaya sreda: vestnik MGKHPA Decorative art and subject-spatial environment: Bulletin of MGHPA, 2015, No. 3, pp. 150-159. (In Russian).

5. Drobov L.N. Zhivopis' Belorussii XIX - nachala XX v. [Painting of Belarus in the 19th - early 20th centuries]. Minsk, Vyshehishaya shkola Publ., 1974. 336 p. (In Russian).

6. Shuvalova I.N. (comp.). Ivan Ivanovich Shishkin: perepiska. Dnevnik. Sovremenniki o khudozhnike [lvan Ivanovich Shishkin: correspondence. Diary. Contemporaries about the artist Leningrad, Iskusstvo Publ., 1978. 463 p. (In Russian).

7. Katser M.S. Izobrazitel'noe iskusstvo Belorussii dooktyabr'skogo perioda: ocherki [Fine arts of Belarus of the pre-October period: essays]. Minsk, Nauka i tekhnika Publ., 1969. 204 p. (In Russian).

8. Kolesnikova T.A. Natsional'naya ideya i peizazh [National idea and landscape]. Rossiiskaya kul'tura glazami molodykh uchenykh: Sbornik trudov. Vyp. 13 [Russian culture through the eyes of young scientists: Collection of works. Issue 13]. St. Petersburg, Kult-Inform-Press Publ., 2003, pp. 132-143. (In Russian).

9. Kolesnikova T.A. Natsional'no-romanticheskii peizazh kontsa XIX - nachala XX veka v tvorchestve Ferdinanda Rushchitsa. Diss. kand. iskusstvovedeniya [National-romantic landscape of the late XIX - early XX century in the work of Ferdynand Ruszczyc. Cand. Art sci. diss.]. St. Petersburg, S. n., 2005. 24 p. (In Russian).

10. Kolesnikova T.A. Romanticheskie dramy Yuliusha Slovatskogo v khudozhestvennoi interpretatsii Ferdinanda Rushchitsa [The romantic dramas of Juliusz Slowacki in the artistic interpretation of Ferdynand Ruszczyc]. Kirillov A.A. (ed.). Problemy khudozhestvennogo sinteza [Problems of artistic synthesis: Materials of the conference]. St. Petersburg, GNIUK RIII Publ., 2004, pp. 75-78. (In Russian). 11. Kolesnikova T.A. Simvolika v zhivopisnykh obrazakh Ferdinanda Rushchitsa [Symbolism in the picturesque images of Ferdynand Ruszczyc]. Kirillov A.A. (ed.). Simvol, simvolicheskoe, simvolizatsiya v iskusstve i kul'ture. Problemy yazyka iskusstva [Symbol, symbolic, symbolization in art and culture. Problems of the language of art]. St. Petersburg, GNIUK RIII Publ., 2001, pp. 57-61. (In Russian). 12. Manin V.S. A.I. Kuindzhi [A.I. Kuindzhi]. Manin V.S. (ed.). Arkhip Ivanovich Kuindzhi i ego shkola [Arkhip Ivanovich Kuindzhi and his school: album]. Leningrad, Khudozhnik RSFSR Publ., 1987. 215 p. (In Russian).

13. Prokoptsov V.I. Nebo i zemlya Ferdinanda Rushchitsa [Heaven and Earth of Ferdynand Ruszczyc]. Tret'yakovskaya galereya Tretyakov Gallery, 2018, No. 3, pp. 138-155. Available at: https://www.tg-m.ru/articles/3-2018-60/nebo-i-zemlya-ferdinanda-rushchitsa (accessed: 16.01.2021). (In Russian).

14. Roerich N.K. Rushchits-Vroblevskii [Ruszczyc-Wroblevsky]. Roerich N.K. Listy dnevnika. T. 3: (1942-1947) [Diary sheets. Vol. 3 : (1942-1947)]. Moscow, MTSR Publ., 2002, pp. 599. (In Russian).

15. Suris B.D. Iz istorii svyazei pol'skogo izobrazitel'nogo iskusstva s russkoi khudozhestvennoi kul'turoi [From the history of relations between Polish fine art and Russian artistic culture]. Iskusstvo - Art, 1954, No. 1, pp. 56-66. (In Russian).

16. Tananaeva L.I. K problematike tvorchestva Fendinanda Rushchitsa [On the Problems of Ferdynand Ruszczyc's Creativity]. Borisova E.A. (ed.). Khudozhestvennye protsessy $v$ russkom i pol'skom iskusstve XIX - nachala XX veka [Artistic Processes in Russian and Polish Art of the 19th - early 20th centuries]. Moscow, Nauka Publ., 1977, pp. 69-90. (In Russian).

17. Tananaeva L.I. O nekotorykh aspektakh tvorchestva Ferdinanda Rushchitsa [On some aspects of the work of Ferdynand Ruszczyc]. Vestnik slavyanskikh kul'tur - Bulletin of Slavic Cultures, 2015, No. 3 (37), pp. 194-214. (In Russian).

18. Ferdinand Rushchits: virtual'naya vystavka k 150-letiyu so dnya rozhdeniya [Ferdynand Ruszczyc: virtual exhibition dedicated to the 150th anniversary of his birth]. National Art Museum of the Republic of Belarus [Official site]. Available at: https://www.artmuseum. by/ru/vyst/virt/ferdinand-rushhicz.-virtualnaya-vyistavka-k-150-letiyu-so-dnya-rozhdeniya.html (accessed: 26.01.2021). (In Russian). 19. Shurshina V.A. A.I. Kuindzhi. Ferdinand Rushchits [A.I. Kuindzhi. Ferdynand Ruszczyc]. Shurshin V.A. (comp.). N.K. Rerikh i Litva [N.K. Roerich and Lithuania: exhibition album]. St. Petersburg, St. Petersburg State Museum-Institute of the Roerich Family, 2019, pp. 26-31. (In Russian).

\section{Для цитирования |For citation:}

Филиппова О.Н. Пейзаж в творчестве Фердинанда Рущица // Искусство Евразии [Электронный журнал]. 2021. № 1 (20). C. 64-75. DOI: https://doi.org/10.46748/ARTEURAS.2021.01.005 URL: https://eurasia-art.ru/index.php/art/article/view/167

Filippova O.N. Landscape in the creative work of Ferdynand Ruszczyc. Iskusstvo Evrazii - The Art of Eurasia, 2021, No. 1 (20), pp. 64-75. DOl: https://doi.org/10.46748/ARTEURAS.2021.01.005 Available at: https://eurasia-art.ru/index.php/art/article/view/167 